\title{
Plasma clearance of oral and intravenous cholic acid in subjects with and without chronic liver disease*
}

\author{
I T GILMORE AND R P H THOMPSON $\dagger$
}

\author{
From the Gastrointestinal Laboratory, Rayne Institute, St Thomas' Hospital, London
}

SUMMARY The apparent plasms clearances of tracer amounts of radiolabelled cholic acid given orally or intravenously were compared in 14 control subjects and 20 patients with chronic liver disease. The clearance after oral administration was the more sensitive in detecting chronic liver disease and correlated better with the fasting levels of endogenous serum bile acid. This agrees with the predicted effects on clearance of hepatocellular damage and portal-systemic shunting of blood after the two routes of administration. The estimated hepatic extraction ratio, calculated from the ratio of the oral and intravenous clearances, was $0.77 \pm 0.02$ (mean $\pm S E M$ ) in control subjects, $0.64 \pm 0.03$ in patients with anicteric chronic liver disease, and $0.46 \pm 0.05$ in those with icteric chronic liver disease.

The concentration of endogenous bile acids in blood is a useful marker of liver disease ${ }^{12}$ and of comparable sensitivity to levels of $\alpha$-glutamyl transpeptidase or aspartate aminotransferase. ${ }^{34}$ Paradoxically, the disappearance rate from plasma of intravenously administered radiolabelled bile acids is not as sensitive ${ }^{56}$ but this has not been satisfactorily explained. One possibility is the difference for bile acids between direct administration into the vascular compartment and absorption from the intestine into blood; in the former, elimination from plasma is highly dependent on liver blood flow, whereas in the latter all absorbed bile acid is subject to first-pass extraction and elimination by the normal liver, irrespective of liver blood flow, before reaching peripheral blood. This suggests that the apparent plasma clearance of radiolabelled bile acid given orally would be more sensitive to liver damage than that of bile acid given intravenously, and would correlate more closely with endogenous serum bile acid concentrations. We set out to test this hypothesis, and to evaluate the use of the ratio of the intravenous and oral clearances for measuring hepatic extraction.

\section{Methods}

All studies were approved by the Ethical Committee of the hospital and by the DHSS Isotopes Advisory Committee.

*Some of this work was presented to the British Society of Gastroenterology, Warwick, 1978.

+Correspondence to R P H Thompson.

Received for publication 7 August 1979

\section{SUBJECTS}

Control subjects

This group consisted of 14 hospital inpatients (eight male; six female) aged 21-78 (mean 54) years, without clinical or biochemical evidence of liver disease and not receiving drugs likely to alter liver function or blood flow.

\section{Patients with chronic liver disease}

In this group were 20 patients with histologically proven chronic liver disease, details of whom are shown in Table 1. Age and sex distributions were similar to those of controls.

The patients were divided into anicteric (ACLD) and icteric (ICLD) groups according to the serum bilirubin concentration $\left(<20,>20 \mu \mathrm{mol}^{-1}\right)$.

\section{CLEARANCE ESTIMATIONS}

24- ${ }^{14} \mathrm{C}$-cholic acid (specific activity $50 \mathrm{mCi} \cdot \mathrm{mmol}^{-1}$, Radiochemical Centre, Amersham) and $2,4-{ }^{3} \mathrm{H}$ cholic acid (specific activity $5-15 \mathrm{Ci}^{\mathrm{mmol}} \mathrm{mm}^{-1}$, New England Nuclear) were the radionuclides used, and radiopurity ( $>98 \%$ ) was confirmed by thin-layer chromatography on $0.25 \mathrm{~mm}$ silica gel plates (E. Merck, Darmstadt) using n-butanol : acetic acid : water $(12: 3: 5, \mathrm{v} / \mathrm{v})$. Each was dissolved in $\mathrm{N}$ saline to a concentration of $1 \mu \mathrm{Ci} \cdot \mathrm{ml}^{-1}$, passed through $0 \cdot 22 \mu$ pore membrane filters and stored in sealed ampoules.

In the first three subjects studied, all controls, oral and intravenous clearances were performed three weeks apart using ${ }^{14} \mathrm{C}$-cholic acid for both. Thereafter the clearances were determined simul- 
Table 1 Diagnosis and biochemical findings in 20 patients with chronic liver disease undergoing combined oral/intravenous cholic acid clearance estimations

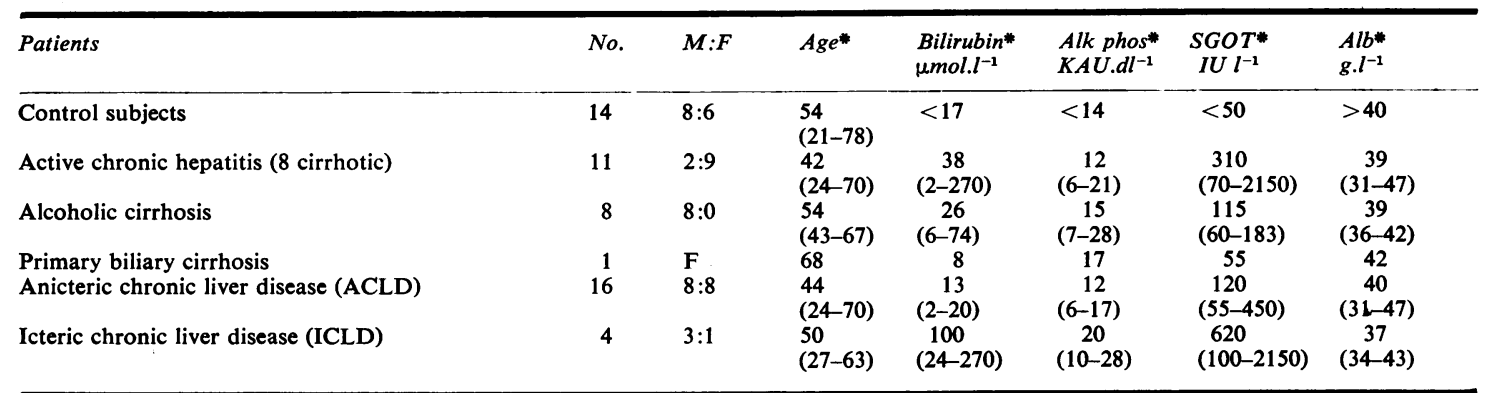

*Mean and range.

taneously using ${ }^{14} \mathrm{C}$ and ${ }^{3} \mathrm{H}$ labelled cholic acid. No difference was noted between the two methods in the control subjects; the simultaneous dual-isotope method was used for all the patients with chronic liver disease.

Subjects were studied at rest after an overnight fast. After an initial blood sample, $5 \mu \mathrm{Ci}{ }^{14} \mathrm{C}$-cholic acid was given intravenously and heparinised blood samples drawn from an indwelling $19 \mathrm{G}$ needle in the other arm at 2, 4, 6, 8, 10,12,15,20,25, and 30 minutes. At this time $15 \mu \mathrm{Ci}{ }^{3} \mathrm{H}$-cholic acid made up to $50 \mathrm{ml}$ with water was given by mouth, and blood samples drawn at 10 minute intervals up to 150 minutes.

Samples were centrifuged, $1 \mathrm{ml}$ plasma added to $10 \mathrm{ml}$ liquid scintillator (NE 260, Nuclear Enterprises, Edinburgh), and counted in a liquid scintillation counter (NE 8132, Nuclear Enterprises) for 30 to 60 minutes until three consecutive counts were in agreement. ${ }^{3} \mathrm{H}$ and ${ }^{14} \mathrm{C}$ counts were separated by adjusting the higher energy channel to exclude all ${ }^{3} \mathrm{H}$ counts and the lower energy channel to include about $20 \%$ of ${ }^{14} \mathrm{C}$ counts; quench correction was performed by the external standard channels ratio method.

\section{SERUM BILE ACID ESTIMATION}

This was performed using a $3 \alpha$-hydroxysteroid dehydrogenase assay after extraction on Amberlite XAD-7 (a gift from Rohm and Haas (UK), Croydon) as previously described. ${ }^{6}$ Concentrations were measured on fasting samples in all the control subjects and in 19 of the patients with chronic liver disease. All control subjects fell within our normal range of $0.5-12.5 \mu \mathrm{mol} .1^{-1}$.

CALCULATION OF RESULTS

For both oral and intravenous administration, plasma clearance rate was calculated from the equation:

$$
\text { Clearance }=\frac{\text { Dose }}{[\mathrm{AUC}] \circ}
$$

where $[\mathrm{AUC}]^{\circ}$ is the area under the plasma concentration-time curve extrapolated to times zero and infinity, calculated using the trapezoid rule. The initial distribution volume (V) after intravenous injection was calculated from:

$$
\mathrm{V}=\frac{\text { Dose }}{\text { concn at } \mathrm{t}=0}
$$

Hepatic extraction ratio (E) was calculated indirectly from the relationship:

$$
1-\mathrm{E}=\frac{\text { Clearance }_{\mathrm{iv}}}{\text { Clearance }_{\text {oral }}}
$$

When hepatic extraction, clearance ${ }_{\text {iv }}$ and haematocrit (H) are known, estimated hepatic blood flow (EHBF) may be calculated from the relationship:

$$
\mathrm{EHBF}=\frac{\text { Clearance }_{\text {iv }}}{\text { E. }(1-\mathrm{H})}
$$

Clearance, distribution volume and estimated hepatic blood flow were standardised for body surface area, calculated from height and weight. ${ }^{7}$ The unpaifed Student's $t$ test was used to test the significance of observed differences between groups.

\section{Results}

\section{CHOLIC ACID CLEARANCE}

\section{Control subjects}

An example of the oral and intravenous plasma disappearance curves is shown in Fig. 1. After intravenous injection, cholic acid clearance was $271 \pm 15 \mathrm{ml} \cdot \mathrm{min}^{-1} \cdot \mathrm{m}^{-2}$ (mean \pm SEM), with an initial distribution volume of $1879 \pm 54 \mathrm{ml} \cdot \mathrm{m}^{-1} \cdot \mathrm{m}^{-2}$. Apparent plasma clearance after oral administration was $1248 \pm 104 \mathrm{ml} \cdot \mathrm{min}^{-1} \cdot \mathrm{m}^{-2}$. The estimated hepatic 

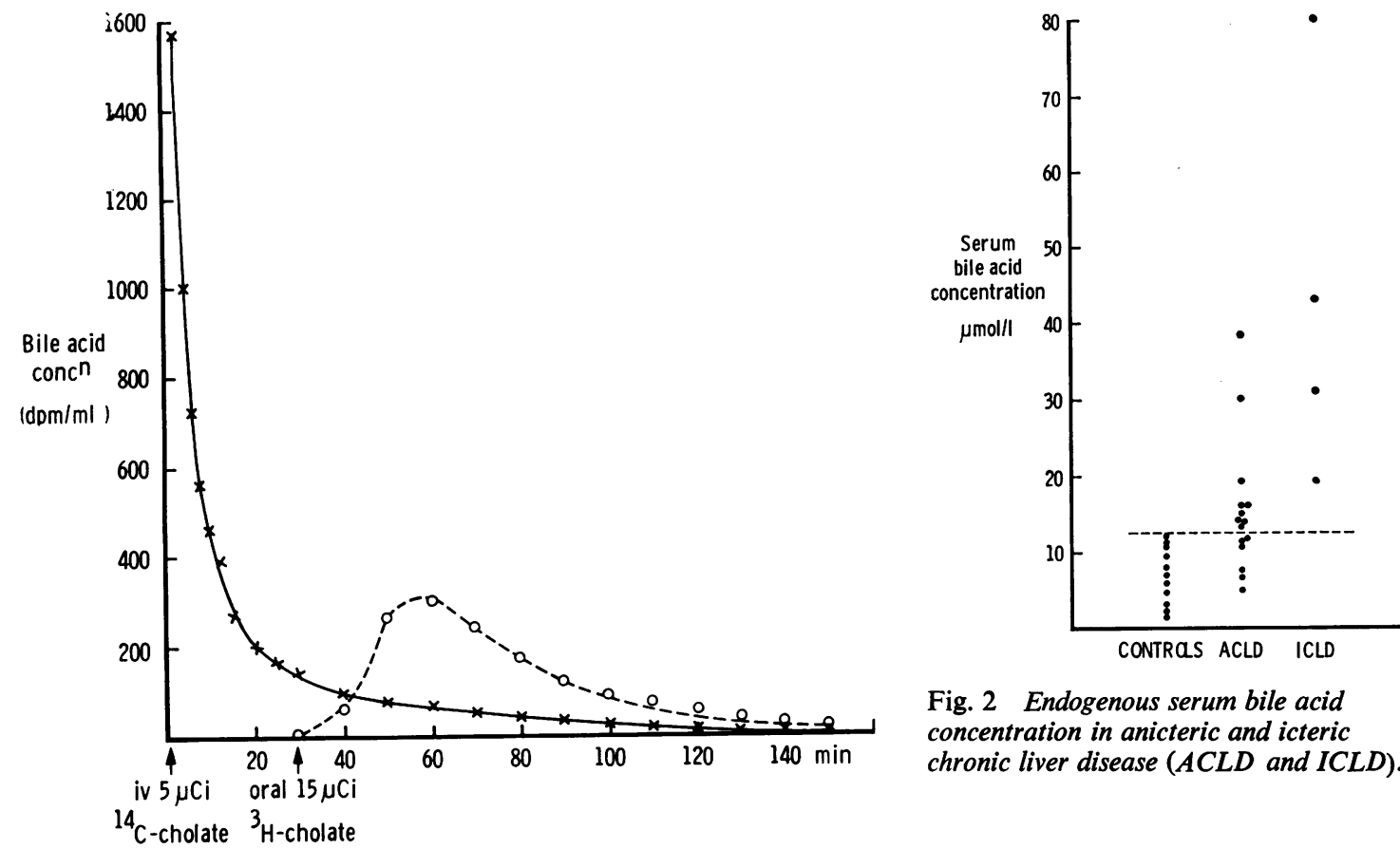

Fig. 1 Plasma bile acid concentration after administration of ${ }^{14} \mathrm{C}$-cholic acid intravenously and ${ }^{3} \mathrm{H}$ cholic acid by mouth.

extraction was therefore $0.77 \pm 0.02$, and EHBF $583 \pm 32 \mathrm{ml} \cdot \mathrm{min}^{-1} \cdot \mathrm{m}^{-2}$.

\section{Patients with chronic liver disease}

The plasma clearances, extraction ratios and distribution volumes are shown in Table 2 . In all groups, the oral clearance was more severely reduced than the intravenous clearance; for instance, in the group with alcoholic cirrhosis the intravenous clearance was maintained within normal limits, whereas the oral clearance was reduced to less than
$50 \%$. The distribution volume was greater in all groups of patients with chronic liver disease than in controls, and was also significantly greater in the icteric than the anicteric group.

FASTING SERUM BILE ACID CONCENTRATIONS Endogenous fasting concentrations of bile acids were abnormal in the four icteric patients and in all but six of those with anicteric chronic liver disease (Fig. 2). The sensitivities of bile acid clearance and fasting serum bile acid concentration for the detection of anicteric chronic liver disease are compared in Figs. 3 and 4. There was a stronger correlation between serum bile acids and oral clearance than between serum bile acids and intravenous clearance, and when results for each were divided into normal

Table 2 Clearances and distribution of ${ }^{14} \mathrm{C}$-cholic acid in patients with chronic liver disease

\begin{tabular}{|c|c|c|c|c|}
\hline Patients & $\begin{array}{l}\text { Volume of distribution } \\
\left(\mathrm{ml} . \mathrm{m}^{-2}\right)\end{array}$ & $\begin{array}{l}\text { Intravenous clearance } \\
\left(\mathrm{ml} \cdot \mathrm{min}^{-1} \mathrm{~m}^{-2}\right)\end{array}$ & $\begin{array}{l}\text { Oral clearance } \\
\left(\mathrm{ml} \cdot \mathrm{min}^{-1} \mathrm{~m}^{-2}\right)\end{array}$ & Extraction ratio \\
\hline $\begin{array}{l}\text { Controls (14) } \\
\text { Active chronic hepatitis (11) } \\
\text { Alcoholic cirrhosis (8) } \\
\text { Primary biliary cirrhosis (1) } \\
\text { Anicteric chronic liver disease (ACLD) (16) } \\
\text { Icteric chronic liver disease (ICLD) (4) }\end{array}$ & $\begin{array}{l}1879 \pm 54 \\
2316 \pm 195 \\
2428 \pm 148 \S \\
2010 \\
2221 \pm 134 * \\
2842 \pm 60 \S\end{array}$ & $\begin{array}{l}271 \pm 15 \\
173 \pm 23 \dagger \\
220 \pm 15 \\
233 \\
219 \pm 19 * \\
99 \pm 22 \S\end{array}$ & $\begin{array}{l}1248 \pm 104 \\
556 \pm 105 \S \\
550 \pm 93 \S \\
696 \\
652 \pm 65 \S \\
194 \pm 54 \S\end{array}$ & $\begin{array}{l}0.77 \pm 0.02 \\
0.62 \pm 0.05 \ddagger \\
0.58 \pm 0.04 \S \\
0.67 \\
0.64 \pm 0.03 \S \\
0.46 \pm 0.05 \S\end{array}$ \\
\hline
\end{tabular}

$*_{\mathrm{P}}<0.05$

$\left.\begin{array}{l}\dagger P<0.02 \\ \ddagger P<0.01\end{array}\right\}$ differences from control subjects

$\$ \mathrm{P}<0.001$ 


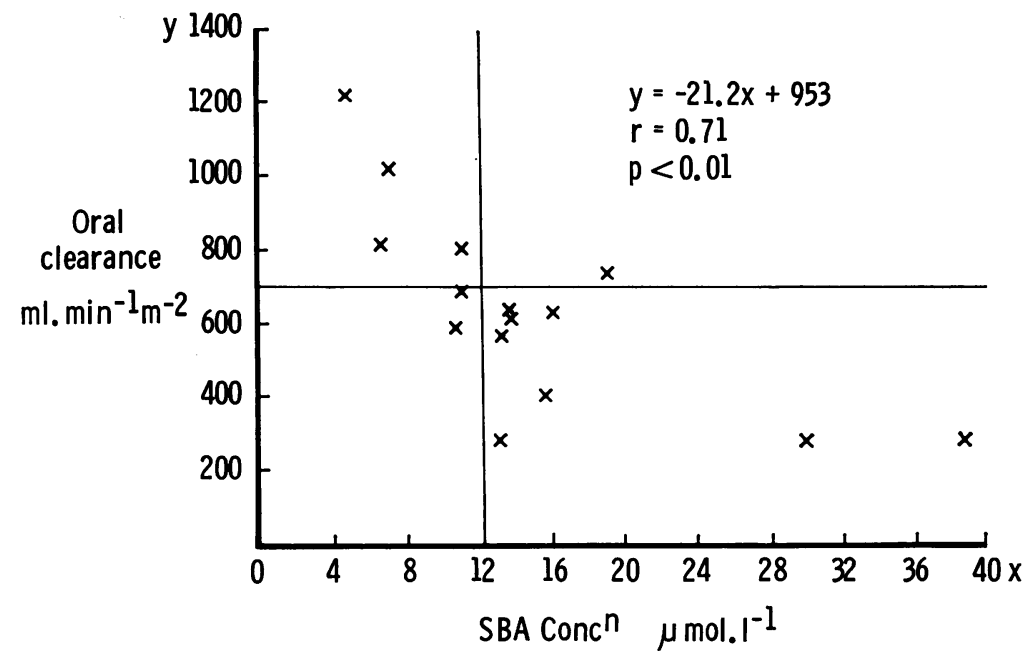

Fig. 3 A comparison of cholic acid clearance after oral administration and endogenous fasting serum bile acid concentration in anicteric chronic liver disease.

Fig. 4 A comparison of cholic acid clearance after intravenous administration and endogenous fasting serum bile acid concentration in anicteric chronic liver disease.

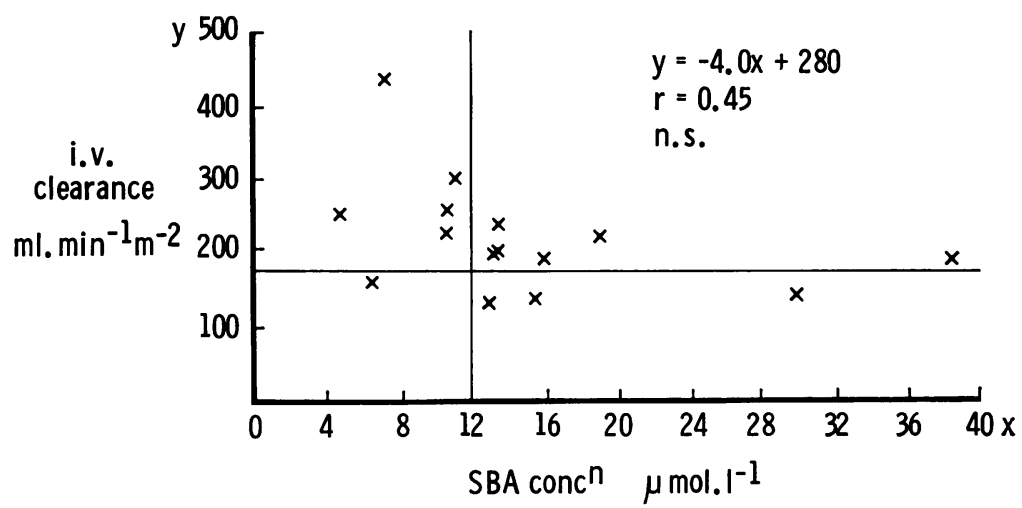

or abnormal, oral clearance and serum bile acid concentration agreed in 13 of 15 patients, whereas intravenous clearance and serum bile acid concentration did so in only eight.

\section{Discussion}

The plasma clearance for cholic acid after intravenous injection in subjects without liver disease, $\left(271 \pm 15 \mathrm{ml} \cdot \mathrm{min}^{-1} \cdot \mathrm{m}^{-2}\right)$, was slower than that reported for the conjugate glycocholic acid in a comparable group $\left(377 \pm 33 \mathrm{ml} \cdot \mathrm{min}^{-1} \cdot \mathrm{m}^{-2}\right) .{ }^{6}$ This agrees with the results of studies in animals in which there was a more rapid hepatic uptake of conjugated than unconjugated bile acids. ${ }^{8-12}$ Furthermore, the initial volume of distribution of ${ }^{14} \mathrm{C}$-cholic acid $(1879 \pm 54$ ml. $\mathrm{m}^{-2}$ ) was smaller than that of ${ }^{14} \mathrm{C}$-glycocholic acid $\left(2330 \pm 277 \mathrm{ml} \cdot \mathrm{m}^{-2}\right)$. This has not previously been reported, but is in keeping with data on proteinbinding, because the conjugates of cholic acid are less bound to albumin than is unconjugated cholic acid..$^{13} 14$

The increase in distribution volume of cholic acid observed in patients with chronic liver disease may be due to abnormalities of protein-binding or to increased plasma volume in cirrhosis. ${ }^{15}$ Whatever the mechanism, this finding underlines the importance of not relying on half-life times $\left(\mathrm{T} \frac{1}{2}\right)$ or fractional elimination rates $\left(\mathrm{k}_{\mathrm{e}}\right)$ for assessing hepatic uptake; the relationship linking clearance, distribution volume $(\mathrm{V})$ and $\mathrm{T}_{\frac{1}{2}}$ or $\mathrm{k}_{\mathrm{e}}$ (clearance $=\mathrm{V} . \mathrm{k}_{\mathrm{e}}$ or $\mathrm{V} . \mathrm{ln}$ $\left.2 / \mathrm{T} \frac{1}{2}\right)$, shows that an increase in $\mathrm{V}$ alone results in a prolongation of $T \frac{1}{2}$ without changes in true clearance or hepatic extraction.

The calculation of the extraction ratio from the plasma clearances after intravenous and oral administration assumes complete absorption of the oral dose from the intestine. This has not been confirmed in this study by intestinal intubation, but complete absorption of unconjugated ${ }^{3} \mathrm{H}$ chenode- 
oxycholic acid from aqueous solution in the jejunum has been demonstrated. ${ }^{16}$ Furthermore, the estimated hepatic extraction $(0.77 \pm 0.02)$ is in close agreement with recent direct measurements of hepatic extraction of cholic acid by hepatic vein catheterisation, where values of 0.70 and 0.72 were obtained in two subjects without liver disease. ${ }^{17}$ It is unlikely that differences in absorption of the orally administered cholic acid would produce the difference in oral clearance between controls and patients with chronic liver disease. Indeed, any malabsorption in liver disease would result in a larger apparent plasma clearance and would therefore tend to obscure any difference from control subjects.

The present work confirms our prediction that measurement of oral clearance of cholic acid would prove more sensitive than that of intravenous clearance in the detection of chronic liver disease. Although it does not provide any evidence on the mechanism, it is likely that it is analogous to the blood concentrations of drugs achieved after oral and intravenous administration. For example, when a substance such as a bile acid with a high hepatic extraction of $80 \%$ is given intravenously, a $10 \%$ reduction in extraction due to liver disease will cause a proportionate $10 \%$ reduction in plasma clearance; however, if the substance is administered orally and fully absorbed, the fraction of the dose reaching peripheral blood from portal blood will be increased from $20 \%$ to $30 \%$ by this $10 \%$ reduction in hepatic extraction, and hence the apparent plasma clearance will fall by more than $50 \%$.

In a recent study using a radioimmunoassay, an oral dose of cholic acid resulted in higher plasma concentrations in cirrhotic patients than in control subjects, particularly when there was portalsystemic shunting. ${ }^{18}$ The oral clearance is sensitive to the effect of portal-systemic shunting of blood, but the relative importance of impaired hepatocellular function and intrahepatic shunting of blood cannot easily be distinguished. ${ }^{19}$

Thus the results of this study of bile acid clearances after both oral and intravenous administration may explain the sensitivity of serum bile acid estimations, and have implications for the dosage and route of administration of drugs in patients with chronic liver disease.

ITG was in receipt of an MRC Training Fellowship. The work was supported by the Special Trustees of St. Thomas' Hospital.

\section{References}

${ }^{1}$ Neale G, Lewis B, Weaver V, Panveliwalla D. Serum bile acids in liver disease. Gut, 1971; 12: 145-52.

${ }^{2}$ Barnes S, Gallo GA, Trash DB, Morris, JS. Diagnostic value of serum bile acid estimations in liver disease. J Clin Path 1975; 28 : 506-9.

${ }^{3}$ Hofmann AF, Korman MG, Krugman S. Sensitivity of serum bile acid assay for detection of liver damage in viral hepatitis type B. Am J Dig Dis 1974; 19: 908-10. ${ }^{4}$ Pennington CR, Ross PE, Bouchier IAD. Serum bile acids in the diagnosis of hepatobiliary disease. Gut 1977; 18: $903-8$.

${ }^{5}$ Thjodleifsson B, Barnes S, Chitranukroh A, Billing BH, Sherlock S. Assessment of the plasma disappearance of cholyl-1 ${ }^{14} \mathrm{C}$-glycine as a test of hepatocellular disease. Gut 1977; 18: 697-702.

${ }^{6}$ Gilmore IT, Thompson RPH. Kinetics of ${ }^{14} \mathrm{C}$-glycocholic acid clearance in normal man and in patients with liver disease. Gut 1978; 19: 1110-15.

${ }^{7}$ DuBois D, DuBois EF. Clinical calorimetry: a formula to estimate the approximate surface area if height and weight be known. Arch Intern Med 1916; 17: 863-71. ${ }^{8}$ O'Máille ERL, Richards TG, Short AH. Acute taurine depletion and maximal rates of hepatic conjugation and secretion of cholic acid in the dog. J Physiol (Lond) 1965; 180: 67-79.

${ }^{9} \mathrm{O}$ 'Máille ERL, Richards TG, Short AH. The influence of conjugation of cholic acid on its uptake and secretion: hepatic extraction of taurocholate and cholate in the dog. J Physiol (Lond) 1967; 189: 337-50.

${ }^{10}$ Hoffman NE, Iser JH, Smallwood RA. Hepatic bile acid transport: effect of conjugation and position of hydroxyl groups. Am J Physiol 1975; 229: 298-302.

${ }^{11}$ Glasinovic JC, Dumont M, Duval M, Erlinger S. Hepatocellular uptake of bile acids in the dog: evidence for a common carrier-mediated transport system. An indicator dilution study. Gastroenterology 1975; 69: 973-81.

${ }^{12}$ Reichen J, Paumgartner G. Uptake of bile acids by perfused rat liver. Am J Physiol 1976; 231: 734-42.

${ }^{13}$ Burke CW, Lewis B, Panveliwalla D, Tabaqchali S. The binding of cholic acid and its taurine conjugate to serum proteins. Clin Chim Acta 1971; 32: 207-14.

${ }^{14}$ Cowen AE, Korman MG, Hofmann AF, Thomas PJ. Plasma disappearance of radioactivity after intravenous injection of labeled bile acids in man. Gastroenterology 1975; 68: 1567-73.

${ }^{15}$ Blendis LM, Ramboer C, Williams R. Studies on the haemodilution anaemia of splenomegaly. Eur $J$ Clin Invest 1970; 1: 54-64.

${ }^{16}$ Ponz de Leon M, Dowling RH. Clinical pharmacology of chenodeoxycholic acid. Gut 1977; 18: 976 (Abstract).

${ }^{17}$ Gilmore IT, Thompson RPH. Direct measurement of the first pass extraction of bile acids by the liver in man. Gut 1978; 19: A971 (Abstract).

${ }^{18}$ Matern S, Haag M, Hans C, Gerok W. Oral cholate tolerance test-an application of specific radioimmunoassays for the determination of serum-conjugated cholic and deoxycholic acids. In Paumgartner G, Stiehl A (eds) Bile acid metabolism in health and disease. Lancaster: M.T.P. Press, 1977; 253-61.

${ }^{19}$ Pessayre D, Lebrec D, Descatoire V, Peignoux M, Benhamou J-P. Mechanism for reduced drug clearance in patients with cirrhosis. Gastroenterology 1978; 74 566-71. 